\title{
Determination of radiotherapeutic target zones for thoracic esophageal squamous cell cancer with lower cervical lymph node metastasis according to CT-images
}

\author{
Xingde $\mathrm{Li}^{1}$, Jin Zhao ${ }^{1}$, Ming Liư ${ }^{2}$, Fushan Zhai ${ }^{2}$, Zhengfei Zhu ${ }^{3}$, Feng $\mathrm{Yu}^{4}$, Mingyun \\ Zhang $^{1}$, Lijie Han ${ }^{1}$, Yue Zhao ${ }^{1}$ and Haiyan Wang ${ }^{1}$ \\ ${ }^{1}$ Cangzhou Central Hospital, Cangzhou, China \\ ${ }^{2}$ Hospital No. 3 of Hebei Medical University, Hebei, China \\ ${ }^{3}$ Tumor Hospital of Fudan University, Shanghai, China \\ ${ }^{4}$ People's Hospital of Qidong City, Nantong, China \\ Correspondence to: Jin Zhao, email: zhaojinzhaoxu@163.com \\ Keywords: esophageal cancer; radiotherapy; lower cervical lymph node; CT-images; supraclavicular zone \\ Received: December 07, $2015 \quad$ Accepted: April 16, 2016 \\ Published: April 28, 2016
}

\section{ABSTRACT}

Esophageal squamous cell carcinoma (ESCC) is a leading cause of cancerrelated deaths worldwide. And radical synchronized chemoradiotherapy has become an important treatment measures for this disease. It is necessary to define the therapeutic target zone based on computer tomography(CT)-images for precise radiotherapy. Therefore, we retrospectively analyzed the regularity of lymph node metastasis in lower cervical section of thoracic esophageal cancer based on CT-images and discussed the range of radiotherapy in supraclavicular zone. The lower cervical lymphatic drainage area was divided into cervical tracheoesophageal groove (CTG), medial supraclavicular zone (MSC zone) and lateral supraclavicular zone (LSC zone) based on CT-images. We found that the rate of lymph node metastasis to medial CTG and MSC zone was relatively high. And rate of lymph node metastasis to the above two zones from middle thoracic section was on an increasing trend with the progress of $T$ stage. Patients at stage T3 and T4 with lymph node metastasis in tracheoesophageal groove in middle thoracic section showed a higher rate of lymph node metastasis in MSC zone. These results demonstrated that the CTG and MSC zone should be clinically included in the supraclavicular target zone for radical radiotherapy, and the T-stage and tumor location should be considered simultaneously.

\section{INTRODUCTION}

Esophageal cancer continues to be one of the most common malignancies worldwide [1] as well as the third most common gastrointestinal malignancy. And squamous cell carcinoma (SCC) is still the predominant form of the disease. The main causes of treatment failure for this disease are local uncontrol and distant metastasis. Some researchers have found that the 5-year survival rate of chemoradiation for esophageal cancer is close to surgery [2-3]. Therefore, radical synchronized chemoradiotherapy has become an important treatment measures for esophageal cancer [4]. But there is no consensus about the determination of radiotherapeutic target zones for esophageal cancer, especially it is of great controversy at present whether the selective lymph node irradiation (ENI) is needed for radical radiotherapy $[5,6]$.

Lymph node status is one of the most important factors that can affect the prognosis of esophageal cancer patients [7]. And it is common for these patients to appear with the supraclavicular lymph node metastasis. Domestic scholars reported that the rate of supraclavicular lymph node metastasis accounted for about $7.1 \%$ to $15.4 \%$ in patients with esophageal cancer when they receive the first radiation therapy, and the 5-year survival rate for these patients with or without supraclavicular lymph node 
Table 1: Clinical data of $\mathbf{3 8 6}$ patients of thoracic esophageal cancer

\begin{tabular}{|l|l|l|l|l|}
\hline Features & $\begin{array}{l}\text { The number of } \\
\text { patients }\end{array}$ & $\begin{array}{l}\text { Cases with lymph node } \\
\text { metastasis }\end{array}$ & $\mathbf{X}^{2}$ & $\mathbf{P}$ \\
\hline Gender & & & & \\
\hline male & 209 & 72 & 0.123 & 0.726 \\
\hline female & 177 & 64 & & \\
\hline Age & & & & \\
\hline$\leq 60$ & 157 & 53 & 0.252 & 0.615 \\
\hline$>60$ & 229 & 83 & & \\
\hline Location of cancer & & & & \\
\hline upper thoracic section & 174 & 80 & 17.528 & 0.000 \\
\hline middle thoracic section & 132 & 39 & & \\
\hline lower thoracic section & 80 & 17 & & \\
\hline T stage of tumor & & & & \\
\hline T1 & 20 & 5 & 1.935 & 0.586 \\
\hline T2 & 91 & 35 & & \\
\hline T3 & 129 & 42 & & \\
\hline T4 & 146 & 54 & & \\
\hline
\end{tabular}

metastasis was $8.2 \%$ and $13.7 \%$, respectively $(\mathrm{P}<0.05)$. Radiation therapy is the effective way to treat the patients with supraclavicular lymph node metastasis.

According to the traditional set of the boundaries of 2D radiotherapeutic zone for supraclavicular field, the annular cartilage or the cricothyroid membrane, and the line at $1 \mathrm{~cm}$ below the lower edge of the subclavian head are respectively the upper and the lower bound [8]. While the junctions between the middle $1 / 3$ and the outer $1 / 3$ of each clavicle are two lateral bounds [9]. In the current era of precise radiotherapy, the target zone for clinical radiotherapy is usually defined by means of CT-images. However, there is no uniform definition and sketch of the supraclavicular zone. Therefore, we retrospectively analyzed the regularity of spontaneous metastasis to lower cervical lymph nodes in 386 thoracic esophageal cancer patients to explore the pattern of supraclavicular lymph node metastasis and find out the high-risk zones of supraclavicular lymph node metastasis. And finally we hope to provide a proposal for reference to define the clinical target zones for supraclavicular radiotherapy of esophageal cancer.

\section{RESULTS}

\section{Distribution characteristics of lymph node metastasis for different zones in lower neck of thoracic esophageal cancer patients}

According to CT-based criteria for diagnosis of lymph node metastasis, the rate of lymph node metastasis in CTG, MSC and LSC zones was 47.2\% (182/386),
$23.1 \%(89 / 386)$ and $4.1 \%(16 / 386)$ respectively in 386 thoracic esophageal squamous cell carcinoma patients. The rate of lymph node metastasis to cervical tracheoesophageal groove from upper, middle and lower thoracic section was respectively $67.2 \%, 37.9 \%$ and $18.8 \%$, of which the rate from upper thoracic section was significantly higher than that from other thoracic sections $\left(\mathrm{X}^{2}=58.634, \mathrm{P}=0.000\right)$. In all cases, the rate of lymph node metastasis from upper, middle and lower thoracic sections to MSC zone was $31.6 \%, 18.9 \%$ and $11.3 \%$ respectively $\left(\mathrm{X}^{2}=14.721, \mathrm{P}=0.001\right)$. And the rate from upper thoracic section was significantly higher than the other two sections $(\mathrm{P}=0.001)$, which was similar to the $\mathrm{CTG}$ zone. The rate of lymph node metastasis from upper, middle and lower thoracic sections to LSC zone was $6.3 \%, 3.0 \%$ and $1.3 \%$ respectively, and there was no significant difference for this zone $\left(\mathrm{X}^{2}=4.175, \mathrm{P}=0.124\right)$. The lymph node metastasis occurred directly from upper thoracic section to LSC zone only in three cases while in the rest cases the lymph node metastasis occurred both in LSC and MSC zones. Table 3 showed the lymph node metastasis to different cervical zones of 386 cases with thoracic esophageal cancer.

Correlation between the rate of lymph node metastasis in different locations and $\mathrm{T}$ stages of the cancer

As the results shown in Table 4, it indicated that the correlation between the rate of lymph node metastasis and the $\mathrm{T}$ stages. The rate of lymph node metastasis to CTG and MSC zone from middle thoracic section of esophageal cancer was on an increasing trend with the progress of $\mathrm{T}$ stages, though the correlation coefficients were only 0.266 and 0.239 respectively by spearman rank correlation analysis. The $\mathrm{T}$ stages of esophageal cancer in upper and lower thoracic sections were not statistically correlated with the rate of lymph node metastasis $(\mathrm{P}>0.05)$ 
Table 2: Bound marks for CT image-based zoning of supraclavicular lymph nodes of patient with esophageal cancer

\begin{tabular}{|c|c|c|c|c|c|c|}
\hline Zones & Upper bound & Lower bound & $\begin{array}{l}\text { Interior } \\
\text { bound }\end{array}$ & Outer bound & Front bound & Rear bound \\
\hline CTG & $\begin{array}{l}\text { The upper edge } \\
\text { of the annular } \\
\text { cartilage }\end{array}$ & $\begin{array}{l}\text { The lower edge } \\
\text { of the external } \\
\text { jugular vein }\end{array}$ & $\begin{array}{l}\text { Outer wall of } \\
\text { trachea and } \\
\text { esophagus }\end{array}$ & $\begin{array}{l}\text { The inside of the } \\
\text { internal carotid artery }\end{array}$ & $\begin{array}{l}\text { Thyroid trailing edge, } \\
\text { the leading edge of } \\
\text { the trachea }\end{array}$ & $\begin{array}{l}\text { Paraspinal } \\
\text { muscles }\end{array}$ \\
\hline MSC & $\begin{array}{l}\text { The upper edge } \\
\text { of the annular } \\
\text { cartilage }\end{array}$ & $\begin{array}{l}\text { Outer edge } \\
\text { of junction of } \\
\text { internal jugular } \\
\text { and subclavian } \\
\text { vein, the } \\
\text { lower edge of } \\
\text { the external } \\
\text { jugular vein }\end{array}$ & $\begin{array}{l}\text { The inside of } \\
\text { the internal } \\
\text { carotid artery }\end{array}$ & $\begin{array}{l}\text { Ligature from } \\
\text { the rear edge of } \\
\text { sternocleidomastoid } \\
\text { muscle to outer edge } \\
\text { of anterior scalenus } \\
\text { muscle }\end{array}$ & $\begin{array}{l}\text { Dorsal side of } \\
\text { sternocleidomastoid } \\
\text { muscle }\end{array}$ & $\begin{array}{l}\text { Ventral side of } \\
\text { anterior scalenus } \\
\text { muscle, dorsal } \\
\text { side of internal } \\
\text { carotid artery }\end{array}$ \\
\hline LSC & $\begin{array}{l}\text { Outer bound of } \\
\text { supraomohyoid } \\
\text { muscle }\end{array}$ & $\begin{array}{l}\text { Lower edge } \\
\text { of external } \\
\text { jugular vein/ } \\
\text { transverse } \\
\text { cervical artery }\end{array}$ & $\begin{array}{l}\text { Outer bound } \\
\text { of upper zone } \\
\text { of } r \text { medial } \\
\text { supraclavicular }\end{array}$ & Ribs or trapezius & Clavicle/Skin & $\begin{array}{l}\text { Ventral side of } \\
\text { Supraomohyoid/ } \\
\text { levator scapula/ } \\
\text { medial scalene }\end{array}$ \\
\hline
\end{tabular}

to medial CTG and MSC zones. But the rate of lymph node metastasis to MSC zone from upper thoracic section was as high as $31.6 \%$, whereas the rate of metastasis to MSC zone from lower thoracic section was only $11.3 \%$ (Table 3).

\section{Relationship between the lymph node metastasis in lower CTG and MSC zones at different $\mathrm{T}$ stages in middle thoracic section esophageal cancer}

As we have concluded that the rate of lymph node metastasis to CTG and MSC zone from middle thoracic section of esophageal cancer was on an increasing trend with the progress of $\mathrm{T}$ stages, we further explored the relationship between the lymph node metastasis in lower CTG and MSC zone at different $\mathrm{T}$ stages in middle thoracic section. The results were shown in Table 5. It indicated that patients with lymph node metastasis to MSC zone accounted for $40 \%$ (20/50) of the patients with lymph node metastasis to $\mathrm{CTG}$ zone $(\mathrm{P}=0.000)$ in middle thoracic section totally. In addition, the lymph node metastasis to MSC zone occurred to about $38.9 \%(7 / 18)$ and $44.4 \%$ $(12 / 27)$ respectively in patients who were classified as stage T3 and T4 accompanied with the metastasis to CTG zone in middle thoracic section of esophageal cancer
$(\mathrm{P}=0.025$ and 0.007$)$. These results implied that lymph node metastasis to tracheoesophageal groove is one of the risk factors for medial supraclavicular lymph node metastasis. But the same conclusion was not drawed at the stage $\mathrm{T} 1$ or $\mathrm{T} 2(\mathrm{P}=0.130)$.

\section{DISCUSSION}

Currently there have no boundaries of lymphatic drainage area for radiotherapy in supraclavicular lymph node zone of esophageal cancer, which was with reference to the recommended treatment for head and neck cancer $[15,16]$. The changes of upper limb position will affect the position of lymph nodes during the localization and radiotherapy [17]. Therefore, we analyzed the spontaneous distribution patterns of lymph node metastasis in lower neck of newly diagnosed esophageal cancer patients for radiation therapy under fixed position, with reference to main markers of muscles, bones and blood vessels.

The characteristics of the lymph node metastasis to lower neck of thoracic esophageal cancer were found as follows in this study. (1) The lymph node metastasis to lateral supraclavicular zone was at a low incidence of $4.1 \%(16 / 386)$ in this study, which was parallel to the medial supraclavicular zone in most cases. However, 

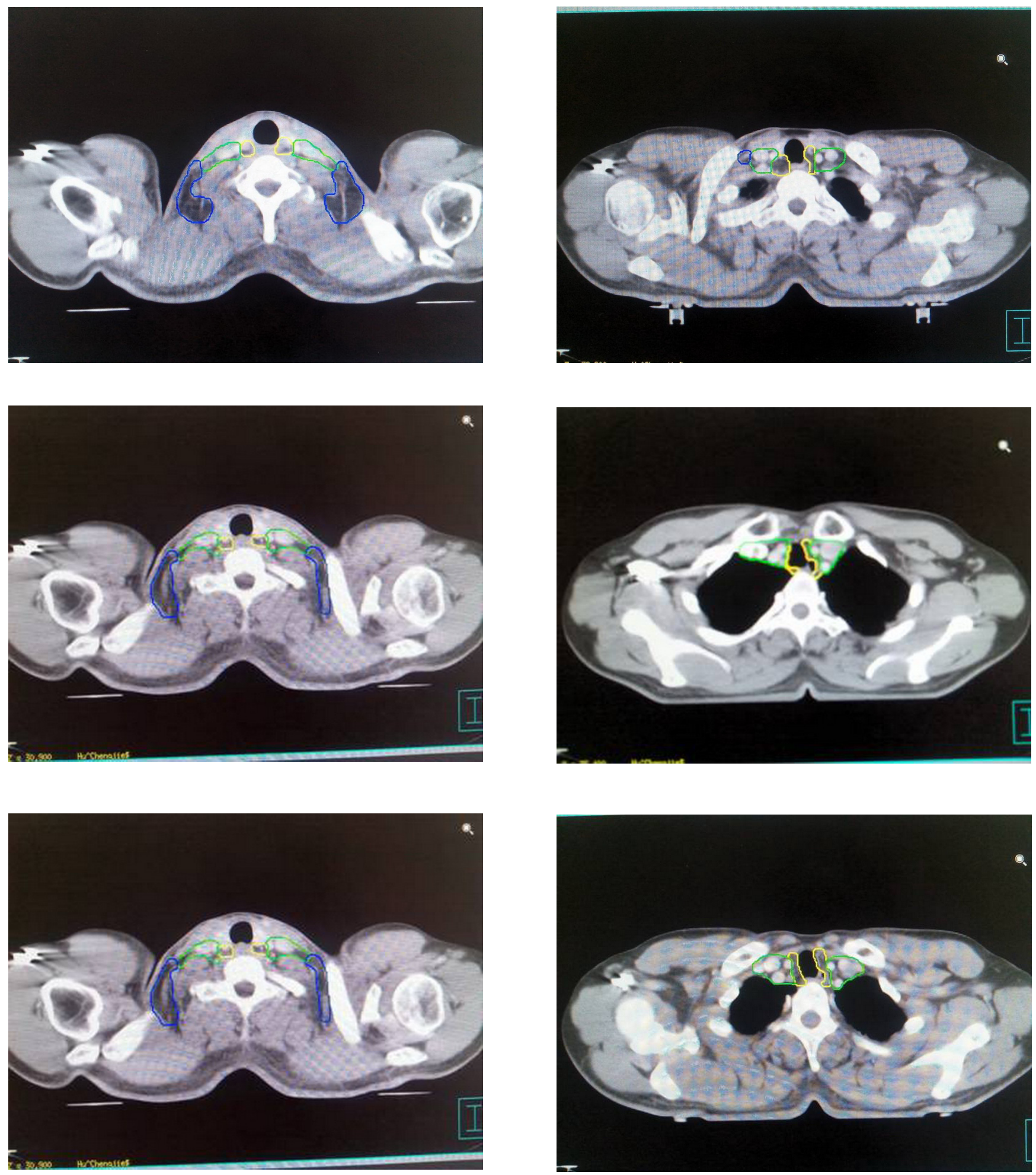

Figure 1: Schematic diagrams of zoning at different bedding planes of CT-imaging in lymphatic drainage area. Note: Zones encircled with yellow line are CTG zones, those with green line are MSC zones and those with blue line are LSC zones. 
Table 3: Analysis of lymph node metastasis to cervical zones from thoracic sections of 386 cases

\begin{tabular}{|l|l|l|l|l|l|}
\hline $\begin{array}{l}\text { Metastasis } \\
\text { location }\end{array}$ & $\begin{array}{l}\text { Upper thoracic } \\
\text { section (174) }\end{array}$ & $\begin{array}{l}\text { Middle thoracic } \\
\text { section (132) }\end{array}$ & $\begin{array}{l}\text { Lower thoracic } \\
\text { section (80) }\end{array}$ & Total & $\boldsymbol{P}$ \\
\hline CTG zone & $117(67.2 \%)$ & $50(37.9 \%)$ & $15(18.8 \%)$ & $182(47.2 \%)$ & 0.000 \\
\hline MSC zone & $55(31.6 \%)$ & $25(18.9 \%)$ & $9(11.3 \%)$ & $89(23.1 \%)$ & 0.001 \\
\hline LSC zone & $11(6.3 \%)$ & $4(3.0 \%)$ & $1(1.3 \%)$ & $16(4.1 \%)$ & 0.124 \\
\hline
\end{tabular}

Table 4: Correlation between the rate of lymph node metastasis in lower neck and the $T$ stages of cancer

\begin{tabular}{|c|c|c|c|c|c|c|}
\hline Locations & T1 & T2 & T3 & T4 & $\begin{array}{l}\text { Correlation } \\
\text { coefficient* }\end{array}$ & $\mathbf{P}$ \\
\hline \multicolumn{7}{|l|}{$\begin{array}{l}\text { Upper thoracic } \\
\text { section }\end{array}$} \\
\hline CTG & $5 / 8(62.5 \%)$ & $40 / 58(69.0 \%)$ & $28 / 49(57.1 \%)$ & $44 / 59(74.6 \%)$ & 0.055 & 0.474 \\
\hline $\mathrm{MSC}$ & $2 / 8(25.0 \%)$ & $22 / 58(37.9 \%)$ & $13 / 49(26.5 \%)$ & $18 / 59(30.5 \%)$ & -0.048 & 0.529 \\
\hline \multicolumn{7}{|c|}{\begin{tabular}{ll|l}
$\begin{array}{l}\text { Middle } \\
\text { section }\end{array}$ & thoracic & \\
\end{tabular}} \\
\hline CTG & $2 / 12(16.7 \%)$ & $3 / 23(13.0 \%)$ & \begin{tabular}{|l|}
$18 / 42(42.9 \%)$ \\
\end{tabular} & $27 / 55(49.1 \%)$ & 0.266 & 0.002 \\
\hline MSC & $0 / 12(0)$ & $1 / 23(4.3 \%)$ & $9 / 42(21.4 \%)$ & $15 / 55(27.3 \%)$ & 0.239 & 0.006 \\
\hline \multicolumn{7}{|c|}{\begin{tabular}{|l|l|l|} 
Lower & thoracic & \\
section & & \\
\end{tabular}} \\
\hline CTG & - & $4 / 10(40.0 \%)$ & $5 / 38(13.2 \%)$ & 6/32(18.8\%) & -0.078 & 0.493 \\
\hline MSC & - & $3 / 10(30.0 \%)$ & $4 / 38(10.5 \%)$ & $2 / 32(6.3 \%)$ & -0.191 & 0.091 \\
\hline
\end{tabular}

*: Coefficient of correlation means Spearman rank correlation coefficient

further study is needed to explore whether metastasis to the two zones is correlated to each other. (2) The target sites for lymph node metastasis of esophageal cancer were dominantly the MSC and CTG zones. As shown in Table 3 , the rates of lymph node metastasis to the MSC (23.1 $\%, 89 / 386)$ and CTG $(47.2 \%, 182 / 386)$ zones indicated an increasing trend from lateral to medial zone. Udagawa et al. [18] reported that the lymph node metastasis occurred mostly along tracheal/laryngeal nerve chain after threefield lymph node dissection, then around the scalene in front of the internal jugular vein, and in transverse cervical artery lymph node at last. The similar pattern was also observed in our study. Therefore, only the MSC and CTG zones are the target zones in clinical target volume (CTV) if prophylactic irradiation to supraclavicular zone is necessary for thoracic esophageal cancer patients.

Some studies have proven that the maximal tumor diameter of esophageal cancer in CT-images directly reflects the range of tumor infiltration. And the deeper the tumor invades, the more opportunities tumor cells can invade into lymphatic vessels [19-21]. In our study, we have proven that $\mathrm{T}$ stage of tumor in upper thoracic section was insignificantly correlated with the rate of lymph node metastasis to medial CTG and MSC zone $(\mathrm{P}>0.05)$. However, the rate of lymph node metastasis to the two zones was both relatively high. Therefore, it is recommended to perform the preventive irradiation in both the CTG and MSC zones for this section regardless of its T stage. The rate of lymph node metastasis to CTG and MSC zones from middle thoracic section was on an increasing trend with the progress of $\mathrm{T}$ stage. Furthermore, the rate of lymph node metastasis to MSC zone was relatively high in patients who were classified as stage T3 and T4 accompanied with the metastasis to CTG zone in middle thoracic section. These results implied that lymph node metastasis to tracheoesophageal groove is one of the risk factors of medial supraclavicular lymph node metastasis. Therefore, it is necessary to define the individualized supraclavicular target zone for radical radiotherapy in middle thoracic section of esophageal cancer according to $\mathrm{T}$ stage and the presence of lymph node metastasis to CTG zone.

There were several shortcomings in this study however. Firstly, the present study was a single center retrospective study. Secondly, the correlation analysis of differentiation degree of tumor tissue was not performed due to the lack of pathological report of the cellular differentiation of tumor in some patients. Moreover, the diagnosis of lymph node metastasis in this study was based on iconographic data instead of pathological evidence. However, the specificity of diagnosis of lymph node metastasis based on CT-images can reach 95\% [23] to $98.47 \%$ [5] when the short diameter of the lymph node is more than $10 \mathrm{~mm}$ or the lymph node is visible in CTG zone. Unlike surgery, we couldn't make a pathological diagnosis for each lymph node for the patients received radiotherapy. CT is thebasisof radiation targetvolume delineation. Therefore, the iconographic diagnosis of lymph node metastasis is credible.

In short, the delineated supraclavicular target zone 

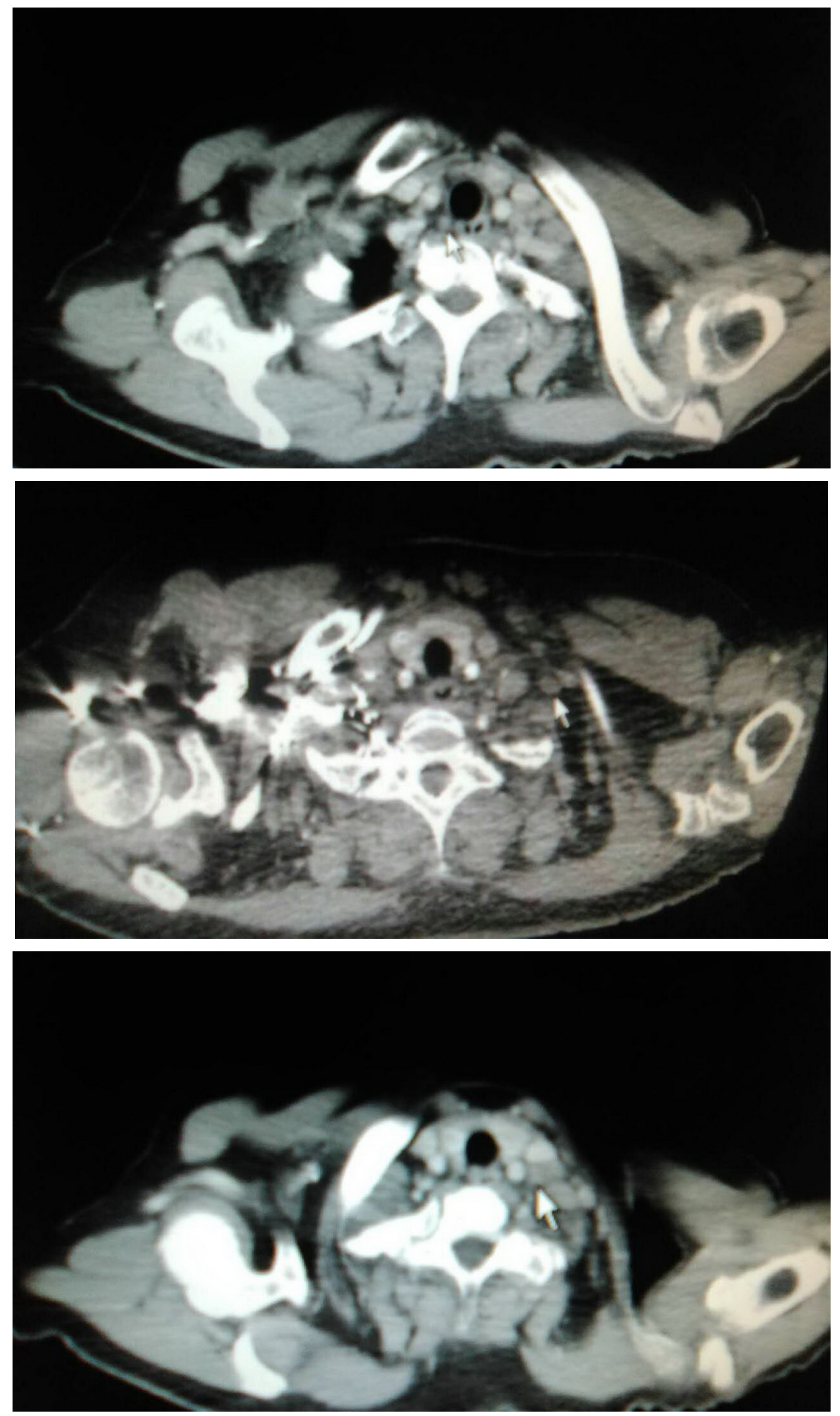

Figure 2: Lymph node metastasis in CTG, MSC and LSC zones, respectively (pointed out by the white arrow). 
Table 5: Relationship between the lymph node metastasis in lower CTG zone at different $T$ stages of esophageal cancer and the lymph node metastasis in MSC zone (cases) in middle thoracic section

\begin{tabular}{|l|l|l|l|l|l|l|l|l|l|l|}
\hline & \multicolumn{3}{|l}{ T1 } & \multicolumn{2}{l|}{ T2 } & \multicolumn{2}{l|}{ T3 } & \multicolumn{2}{l|}{ Total } \\
\cline { 2 - 11 } & $\begin{array}{l}\text { CTG } \\
(-)\end{array}$ & CTG (+) & $\begin{array}{l}\text { CTG } \\
(-)\end{array}$ & CTG (+) & $\begin{array}{l}\text { CTG } \\
(-)\end{array}$ & CTG (+) & $\begin{array}{l}\text { CTG } \\
(-)\end{array}$ & CTG (+) & $\begin{array}{l}\text { CTG } \\
(-)\end{array}$ & CTG (+) \\
\hline MSC (-) & 10 & 2 & 20 & 2 & 22 & 11 & 25 & 15 & 76 & 30 \\
\hline MSC (+) & 0 & 0 & 0 & 1 & 2 & 7 & 3 & 12 & 5 & 20 \\
\hline$P^{*}$ & - & 0.130 & & 0.025 & & 0.007 & & 0.000 \\
\hline
\end{tabular}

*: $P$ value is the possibility calculated from Fisher's exact test.

for radiotherapy of esophageal cancer should be selected according to individual clinical situation in need of prophylactic irradiation. The target zones for prophylactic irradiation should include the bilateral MSC and CTG zones as recommended. It is necessary in the future to retrospectively analyze the distribution pattern and clinical correlation of esophageal cancer recurrence in lymph node draining area, and to conduct prospective clinical study on the definition of individualized target area delineation in supraclavicular zone.

\section{MATERIALS AND METHODS}

\section{Clinical data}

Data of 386 patients with newly diagnosed esophageal cancer and treated in radiotherapy department of Cangzhou Central Hospital from October 2009 to August 2014 was collected. All cases, including 209 males and 177 females, with a median age of 58 years (40-81 years), were definitely diagnosed by pathology of esophageal squamous cell carcinoma. Among them, there were 174 cases with cancer in upper thoracic section, 132 cases in middle thoracic section and 80 cases in lower thoracic section. According to clinical staging criteria (draft) of Chinese non-surgical treatment of esophageal cancer [22], there were 20,91, 129 and 146 cases respectively at the stage of $\mathrm{T} 1, \mathrm{~T} 2, \mathrm{~T} 3$ and $\mathrm{T} 4$ in order. The clinical data of these patients is shown in Table 1 in detail.

\section{Radiotherapy methods}

The position of all patients was fixed with thermoplastic omentum after both hands held the contralateral elbow and raised to contact forehead. Then the patients received the enhanced cervical and thoracic $\mathrm{CT}$ scan ranging from cricothyroid membrane to costophrenic angle horizontal, with the slice thickness of
$5 \mathrm{~mm}$. The CT-images were reconstructed into 3-D images and transmitted into the planning system (USA, Eclipse) after digitization.

\section{Criteria for defining lymph node metastasis}

(1) Short diameter of lymph node in soft-tissue window is longer than $10 \mathrm{~mm}$ on enhanced CT-images, or there are more than three lymph nodes in the same diagnostic zone[10];

(2) Nodules formed in tracheoesophageal groove.

Meeting one of the above two points can be diagnosed as lymph node metastasis[11, 12]. At least one physician from radiotherapy department and one from radiology department read CT images individually in the diagnosis of lymph node metastasis. Or, the images should be read and discussed by a physician of higher rank in case of controversial reading until a consensus for diagnosis is concluded and then recorded.

\section{Lymph node zoning}

According to the reported method [13, 14], with muscles, bones and blood vessels as the main marker points, the lymph nodes in lower neck of esophageal cancer were zoned as long as they can be delineated based on CT-images in principle. In addition, the zones were divided into three zones, cervical tracheoesophageal groove (CTG zone), medial supraclavicular zone (MSC zone) and lateral supraclavicular zone (LSC zone). Moreover, six bounds for each zone were defined in Table 2. And the schematic diagrams of zoning at different CT bedding planes were indicated in Figure 1.

\section{Statistical methods}

The zone-to-zone metastasis of lymph node was analyzed by means of $\mathrm{x} 2$ test. Spearman correlation analysis and Fisher's exact test were used for intergroup 
comparison. All statistical analyses were performed using SPSS 19.0 statistical software (SPSS Inc, Chicago, IL, USA). P-values $<0.05$ were considered statistically significant.

\section{ACKNOWLEDGMENTS}

This work was supported by Cangzhou City Science \& Technology Research and Develepment Planning Project (No. 131302036).

\section{CONFLICTS OF INTERESTS}

The authors declare that there is no conflict of interests regarding the publication of this article.

\section{REFERENCES}

1. Siegel RL, Miller KD, Jemal A. Cancer statistics, 2015. CA Cancer J Clin. 2015;65:5-29.

2. Cooper JS, Guo MD, Herskovic A, Macdonald JS, Martenson JA Jr, Al-Sarraf M, Byhardt R, Russell AH, Beitler JJ, Spencer S, Asbell SO, Graham MV, Leichman LL.Chemoradiotherapy of locally advanced esophageal cancer: long-term follow-up of a prospective randomized trial (RTOG 85-01). Radiation Therapy Oncology Group. JAMA. 1999;281:1623-1627.

3. Zhao KL, Shi XH, Jiang GL, Yao WQ, Guo XM, Wu GD, Zhu LX. Late course accelerated hyperfractionated radiotherapy plus concurrent chemotherapy for squamous cell carcinoma of the esophagus: a phase III randomized study. Int J Radiat Oncol Biol Phys. 2005;62:1014-1020.

4. Stahl M, Budach W, Meyer HJ, Cervantes A on behalf of the esmo Guidelines Working Group. Esophageal cancer: clinical practice guidelines for diagnosis, treatment and follow-up. Ann Oncol. 2010;21:v46-v49.

5. Liu M, Zhao K, Chen Y, Jiang GL. Evaluation of the value of ENI in radiotherapy for cervical and upper thoracic esophageal cancer: a retrospective analysis. Radiat Oncol. 2014;25;9:232.

6. Dong H, Zhu SC, Su JW, Shen WB, Liu ZK, Li J. Study on ENI and IFI failure mode in radical radiotherapy of esophageal cancer. Journal of Radiation Oncology. 2014;23:479-483.

7. Wu SG, Sun JY, Yang LC, Zhou J, Li FY, Li Q, Lin HX, Lin Q, He ZY. Prognosis of patients with esophageal squamous cell carcinoma after esophagectomy using the log odds of positive lymph nodes. Oncotarget. 2015;6:36911-36922. doi: 10.18632/oncotarget.5366.

8. Xiao ZF, Yang ZY, Liang J, Miao YJ, Wang M, Yin WB, Gu XZ, Zhang DC, Zhang RG, Wang LJ. Value of radiotherapy after radical surgery for esophageal cancer: a report of 495 patients. Ann Thorac Surg. 2003;75:331-336.

9. Chen KN, Shi XT, Dou YX, Xu GW. Long-term survival of patients of irradiation in mediastinum and upper/lower section of bilateral collarbone zone after esophageal cancer resection. Chinese Journal of Clinical Oncology. 2004;31:1027-1029.

10. Expert group stage clinical Chinese non-surgical treatment of esophageal cancer. Non-surgical treatment of esophageal cancer clinical staging criteria (draft). Journal of Radiation Oncology. 2010;19:179-180.

11. Kato H, Igaki H, Tachimori $\mathrm{Y}$, Watanabe $\mathrm{H}$, Tsubosa $\mathrm{Y}$, Nakanishi Y. Assessment of cervical lymph node metastasis in the staging of thoracic esophageal cancer. J Surg Oncol. 2000;74:282-285.

12. Takemura M, Osugi H, Takada N, Kinoshita H, Higashino M. Prognostic factors in patients with squamous esophageal cancer associated with solitary lymph node metastasis after esophagectomy and extended lymphadenectomy. Oncol Rep. 2003;10:75-80.

13. Gu YJ, Wang MH, Xiang JQ, Ma LF. Discussion of the clinical significance of CT-based observation of the lymph node metastasis in tracheoesophageal groove of thoracic esophageal cancer. Chinese Journal of Radiation Medicine. 2002;36:139-141.

14. Liu M, Chen Y, Fu X, Zhao K, Jiang GL. Proposed revision of CT-based cervical and thoracic lymph node levels for esophageal cancer in UICC 7th version. Radiother.Oncol. 2014;113:175-181.

15. Atean I, Pointreau Y, Ouldamer L, Monghal C, Bougnoux A, Bera G, Barillot I. A simplified CT-based definition of the supraclavicular and infraclavicular nodal volumes in breast cancer. Cancer Radiother. 2013;17:39-43.

16. Grégoire V, Coche E, Cosnard G, Hamoir M, Reychler H. Selection and delineation of lymph node target volumes in head and neck conformal radiotherapy. Proposal for standardizing terminology and procedure based on the surgical experience. Radiother Oncol. 2000;56:135-150.

17. Nowak PJ, Wijers OB, Lagerwaard FJ, Levendag PC. A three-dimensional CT-based target definition for elective irradiation of the neck. Int J Radiat Oncol Biol Phys. 1999;45:33-39.

18. Martinez-Monge R, Fernandes PS, Gupta N, Gahbauer R. Cross-sectional nodal atlas: a tool for the definition of clinical target volumes in three-dimensional radiation therapy planning. Radiology. 1999;211:815-828.

19. Udagawa $H$, Akiyama H. Surgical treatment of esophageal cancer: Tokyo experience of the three-field thchnique. Dis Esophagus. 2001;14:110-114.

20. Tachibana M, Dhar DK, Kinugasa S, Kotoh T, Shibakita M, Ohno S, Masunaga R, Kubota H, Nagasue N. Esophageal cancer with distant lymph node metastasis: prognostic significance of metastasis lymph node ratio. J Clin Gastroenterol. 2000;31:318-322.

21. Shimada H, Nabeya Y, Matsubara H, Okazumi S, Shiratori T, Shimizu T, Aoki T, Shuto K, Akutsu Y, Ochiai T. Prediction of lymph node status in patients with superficial 
esophageal cancer: analysis of 160 surgically resected cancer. Am J Surg. 2006;191:250-254.

22. Expert group stage clinical Chinese non-surgical treatment of esophageal cancer. Non-surgical treatment of esophageal cancer clinical staging criteria (draft). Journal of Radiation Oncology. 2010;19:179-180.
23. Greenberg J, Durkin M, Van Drunen M, Aranha GV. Computed tomography or EUS in preoperative staging of gastric and esophageal tumors. Surgery. 1994;116:696-701. 